\title{
FENOLOGIA E PRODUTIVIDADE DA FRUTA-PÃO (Artocarpus altilis) E DA JACA (A. heterophyllus) NA AMAZÔNIA CENTRAL ${ }^{1}$
}

\author{
Martha de Aguiar FALCÃO ${ }^{2}$, Charles R. CLEMENT ${ }^{3}$, João Batista Moreira \\ GOMES $^{3}$, Wanders B. CHÁVEZ FLORES ${ }^{4}$, Filomena Ferreira SANTIAGO ${ }^{5}$, \\ Vilma Pereira FREITAS ${ }^{6}$
}

RESUMO - A fruta-pão (Artocarpus altilis e a jaca (A. heterophyllus) são comumente cultivadas na Amazônia. Ambas apresentaram vários picos de floração ao longo do ano. A fruta-pào floresceu na época chuvosa e na de estiagem, enquanto que a jaca floresceu principalmente na época chuvosa. A proporção de inflorescências estaminadas e pistiladas na fruta-pão alternou irregularmente ao longo do ano, enquanto as flores pistiladas na jaca foram quase sempre mais frequentes. Os frutos da fruta-pão estavam presentes durante a maioria do ano, com picos de abundância no início da época chuvosa (janeiro a março) e na época de estiagem (agosto a outubro), enquanto frutos de jaca estavam presentes com abundância na época chuvosa de 1988 (janeiro a março) e na época de estiagem de 1988 e 1989 (julho a setembro). O vingamento dos frutos da fruta-pão foi maior que o da jaca, com médias de $76 \%$ e $48 \%$ por semestre, respectivamente. Tanto a fruta-pão como a jaca apresentaram uma acentuada caída de frutos entre o vingamento e a maturação, com médias de $36 \%$ e $28 \%$ por ano, respectivamente. Embora o número de frutos produzidos por planta não foi muito diferente (médias de 53 e 45 por planta, respectivamente), a produtividade da jaca foi expressivamente maior (475 kg/planta) que a da fruta-pão (48 kg/planta), porque os frutos da jaca são maiores que os da fruta-pão (médias de $8,9 \mathrm{~kg}$ e $1,1 \mathrm{~kg}$, respectivamente). As abelhas foram os principais insetos visitantes, sendo muito mais numerosas que as formigas, borboletas ou moscas.

Palavras chave: floração, frutificação, vingamento, mudança foliar, insetos visitantes

Phenology and Yield of Breadfruit (Artocarpus altilis) and Jackfruit (A. heterophylus) in Central Amazonia

ABSTRACT - The breadfruit (Artocarpus altilis (Parkinson) Fosberg) and the jackfruit (A. heterophyllus Lamk) are native to Oceania and south Asia, respectively, and were domesticated for their starchy fruits and nutrient rich seeds. Both are commonly cultivated in Amazonia, in both urban and rural settings. Both species presented various flowering peaks during the year, with breadfruit flowering in both the rainy and the dry seasons, while jackfruit flowered principally in the rainy season. The proportion of staminate and pistilate flowers of breadfruit alternated irregularly during the year, while the pistilate flowers of jackfruit were generally most abundant. Breadfruits were present on the trees during most of the year, with peaks of abundance in the early rainy (January to March) and late dry seasons (August to October), while jackfruits were abundant in the rainy season of 1988 (January to March) and the dry season of 1988 and 1989 (July to September). Fruit set of breadfruit was greater than that of jackfruit (means of $76 \%$ and $48 \%$ per semester, respectively). Both breadfruit and jackfruit presented pronounced fruit abortion between fruit set and maturation (means of $36 \%$ and $28 \%$ per year, respectively). Although fruit number produced per tree was not much different (means of 53 and 45 , respectively), estimated jackfruit yield was much greater ( $475 \mathrm{~kg} /$ tree) than that of breadfruit ( $48 \mathrm{~kg} /$ tree), because jackfruits were much larger than breadfruits (means of $8.9 \mathrm{~kg}$ and $1.1 \mathrm{~kg}$, respectively). Bees were the principal insect visitors, always more numerous than ants, butterflies or flies.

Key-words: flowering, fruiting, fruit set, leaf change, insect visitors

'Pesquisa feita com apoio do convênio UA/INPA entre 1987 e 1990, e do CNPq entre 1997 e 2000. ${ }^{2}$ Bolsista do INPA, modalidade DTI. Av. Col. Teixeira, 386, Cond. Rio Tupana, Apto. 602-A, 69030-481 Manaus, AM, Brasil. E-mail: mfalcao@internext,com.br

${ }^{3}$ INPA, Cx. Postal 478, 69011-970 Manaus, AM, Brasil.

${ }^{4}$ Doutorando em Botânica, PPGBTRN/INPA, a/c CPCA/INPA, Cx. Postal 478.

${ }^{5}$ Bolsista do CNPq; atual bolsista do INPA, modalidade PCI, com apoio do CNPq.

${ }^{6}$ Bolsista do CNPq, IPAAM, Rua Recife, 3280 - Parque 10, 69057-002 Manaus, AM, Brasil. 


\section{INTRODUÇÃO}

As espécies Artocarpus altilis (Parkinson) Fosberg, fruta pão, e $A$. heterophyllus Lamk, jaca, da família Moraceae, são originárias da Oceania e do sul da Asia, respectivamente. Ambas são cosmopolitas e comumente cultivadas em toda Amazônia. Sabe-se que sementes da fruta-pão foram introduzidas no Pará em 1801 e no Rio de Janeiro em 1809 , procedentes das Antilhas (Corrêa, 1926). A jaca foi introduzida no Brasil em 1809, possivelmente em Belém, procedente de Cayenne, Guiana Francesa (Patiño, 1969).

Árvores da fruta-pão atingem de 15 a $20 \mathrm{~m}$ de altura, com $1,2 \mathrm{~m}$ de diâmetro do tronco a altura do peito. As inflorescências são unissexuais e são produzidas nas axilas das folhas; as masculinas são pêndulas e um tanto esponjosas, enquanto as femininas são globosas e eretas; uma inflorescência chega a ostentar de 1.500 a 2.000 flores (Jarrett, 1976). A proporçãao de inflorescências masculinas em uma árvore é de $60-80 \%$, e se forem tocadas durante a ântese, elas liberam uma nuvem de pólen, sugerindo que a polinização maior é anemófila (vento). As flores são polinizadas e fertilizadas no periodo de 3 a 6 dias (Barrau, 1976), sendo possivel a autofecundação pela presença de flores masculinas e femininas no mesmo período. Os frutos sincárpicos são globosos ou oblongos, amareloesverdeados, com 50 a 60 sementes de cor marrom-claro, usadas como alimento, cozidas ou assadas, pois possuem ao redor de $13,3 \%$ de proteinas (Quijano \& Arango, 1979; Negron de Bravo et al., 1983; Cavalcante, 1991). As plantas possuem látex branco, usado para calafetar embarcações (Prance \& Silva, 1975; Ragone, 1997). A frutapão é adaptada às regiões tropicais, com temperatura de 20 a $35^{\circ} \mathrm{C}$, regime de chuvas de 2.000 a $3.000 \mathrm{~mm}$, e umidade relativa do ar de 70 a $90 \%$ (Ragone, 1997).

A jaqueira é uma árvore de copa irregular de 10 a $25 \mathrm{~m}$ de altura, com tronco cilíndrico, muito ramificado e numerosos canais de látex. As inflorescências são pêndulas, em forma de espigas, solitárias, unissexuais e axilares. As inflorescências pistiladas (femininas) são verdes, solitárias e nascem nos troncos ou galhos maiores, são oblongas, elipsóides ou clavadas, maiores que as inflorescências masculinas; as inflorescências estaminadas (masculinas) são verdes, cilindricas ou elipsóides, e nascem em fascículos nos ramos terminais (Barrau, 1976). As flores são pequenas, sendo as masculinas com cálice bilobado e um único estame; as femininas apresentam cálice tubular, ovário oblongo, comprido, e estígma claviforme. O fruto sincárpico é globoso, até $80 \mathrm{~cm}$ de comprimento por $30 \mathrm{~cm}$ de largura, pesando de 10 a $25 \mathrm{~kg}$; as sementes são envolvidas por um arilo fibroso, macio, amarelo, com cheiro forte característico. $\mathrm{O}$ fruto é comestível, usado na preparação de doces, compotas, sorvetes e cremes. As sementes cozidas são ótimo alimento, considerada nutritivo e 
tônica, com composição similar à da fruta-pão (Prance \& Silva, 1975; Cavalcante, 1991). Na Índia é tambem usado em sopas e outros pratos culinários, bem como em coquetéis de frutas e vegetais. $\mathrm{O}$ látex serve para vários fins industriais, e na China é usado como medicinal (Teaotia \& Chauhan, 1969; Thomas, 1980; Bennett \& Nozzollilo, 1988; Narasimham, 1990; Soepadmo, 1992; Ragone, 1997).

Wielgolaski (1974) definiu a fenologia como o estudo do efeito da periodicidade das condições climáticas, influenciado pelas condições edáficas e ecológicas em geral, sobre o ciclo biológico das plantas, especialmente sobre os orgãos reprodutivos e de crescimento vegetativo.

conhecimento da fenologia ajuda o planejamento e manejo do plantio e a comercialização dos frutos. O objetivo deste trabalho foi observar e contrastar a fenologia e a produtividade de fruta-pão e jaca durante três anos na Amazônia central.

\section{MATERIAL E MÉTODOS}

Este estudo foi iniciado em agosto de 1987 no ensaio "Consórcio com três espécies frutiferas: fruta-pão (Artocarpus altilis (Parkinson) Fosberg), jaca (A. heterophyllus Lamk) e pupunha (Bactris gasipaes H.B.K.)," popularmente chamado da "Floresta de alimentos" (Arkcoll, 1982), instalado em 1979 no campus III do Instituto Nacional de Pesquisas da Amazônia - INPA, Avenida Efigênio Sales, $s / n$, Manaus,
Amazonas, Brasil. As mudas da frutapão e da jaca foram obtidas de árvores cultivadas nos quintais em Manaus, selecionadas apenas por sanidade, vigor e produção de frutos; a fruta-pão usada foi daquela com sementes, pois a fruta-pão de massa (sem sementes) é muita rara em Manaus. O tipo de solo é latossolo amarelo, textura média a arenosa (N. P. Falcão, INPA, com. pess.). O clima é "Afi," no esquema de Köppen, com médias anuais de $2.478 \mathrm{~mm}$ de chuva e temperatura de $25,6^{\circ} \mathrm{C}$ (Ribeiro, 1976). Os dados climáticos (Figs. 1A, 2A) foram obtidos da Estação Meteorológica do Ministério de Agricultura, em Manaus.

Foram selecionadas ao acaso 12 árvores de fruta-pão e 12 de jaca nas parcelas consorciadas. A avaliação da fenologia seguiu Falcão (1993) no período de agosto 1987 a junho de 1990. Em cada árvore selecionou-se três galhos ao acaso para as observações de mudança foliar e contagem de flores e frutos, e envolviu-se 10 inflorescências femininas com saquinhos de morim, de malha bem fina, para observação da auto-polinização não assistida. No período de 1984 a 1986, 32 frutos de fruta-pão e 11 de jaca foram pesados e separados em sementes, polpa (só jaca) e partes não comestíveis. No período 1987 e 1988 , contou-se a queda de frutos imaturos e a produção de frutos maduros. Os insetos visitantes foram capturados e montados para posterior identificação, retirando-se o pólen que eles transportavam para comparação com o pólen das espécies. 


\section{RESULTADOS E DISCUSSÃO} Floração

A fruta-pão apresentou três picos de floração ao longo de cada ano (Fig. 1B), com picos maiores em 1988 (janeiro/março, abril, julho/setembro) e uma tendência de redução no tamanho dos picos ao longo do periodo de observações. É possivel que esta redução foi devido a falta de adubação. Fownes \& Raynor (1993) observaram apenas um ou dois picos de produção em cultivares da frutapão de massa em Pohnpei (Oceania).

A porcentagem de inflorescências masculinas e femininas variou ao longo do ano (Figs. 1B, 1C), com um máximo de $80 \%$ masculinas em fevereiro 1988, no pico de floração, e um mínimo de $25 \%$ num período quase sem flores. Barrau (1976) observou a mesma proporção máxima, mas a menor proporção observada aqui foi bem inferior ao minima observado por ele $(60 \%)$, possivelmente por ter sido observado num período de pouca floração. Em picos alternados, as inflorescências femininas foram mais abundantes que as masculinas (Fig. 1B), sem relação aparente com a frutificação (Fig. 1D).

Vinte porcento das inflorescências femininas da fruta-pão revestidas com saquinhos de morim durante 15 dias vingaram frutos, sugerindo que a auto-fecundação é possivel. Barrau (1976) havia mencionada esta possibilidade, sem apresentar uma estimativa da taxa de auto-fecundação. Ragone (1997) menciona ainda que inflorescências 'anormais' têm sido observadas com flores masculinas e femininas, sugerindo a existência de uma certa taxa de hermafroditismo.

A jaca floreceu durante quase todo o ano (Fig. 2B), com menor intensidade no período da safra. Em 1988 , houve quatro picos sucessivos de floração (fevereiro, abril/maio, julho, setembro), enquanto houve três picos em 1989, sendo dois sucessivos (abril/maio, julho) e um separado dos outros, perto do final do ano (outubro/ novembro). A floração aconteceu principalmente na época chuvosa e no início da época de estiagem, extendendo durante a maior parte da estiagem (1988), embora com menor intensidade; em 1989 houve uma pausa da floração no final da estiagem (setembro/outubro). No sul da Índia, a floração da jaqueira acontece de dezembro a maio, com variações que dependem das condições agroclimáticas (Teaotia \& Chauhan, 1969).

Observou-se que as inflorescências femininas foram quase sempre mais numerosas que as masculinas ao longo do ano, variando de 50 a $65 \%$ feminina durante os períodos de maior floração (Fig. 2C). Quando teve pouca floração, a proporção feminina aumentou até $100 \%$, como por exemplo em dezembro 1988 e janeiro 1989. Estas proporções contrastam com as da fruta-pão (Fig. 1C), onde as inflorescências masculinas e femininas variaram em abundância ao longo do ano.

$\mathrm{Na}$ jaqueira, das inflorescências femininas revestidas com saquinhos de morim durante 15 dias, nenhuma vingou frutos, sugerindo que não ocorre auto-fecundação não assistida, nem hermafroditismo, diferente do 
que ocorre na fruta-pão. Soepadmo (1992) afirma que ainda não se sabe se a jaca é principalmente anemófila (polinizada pelo vento) ou entomófila (por insetos), embora ambos processos tenham sido comentados.

\section{Frutificação}

Na fruta-pão, o desenvolvimento dos frutos ocorreu quase concomitante à floração (Fig. 1D), com o maior pico de janeiro a março, na época chuvosa, e um pico menor de agosto a outubro, no periodo da estiagem. Durante o maior pico, as árvores chegaram a produzir 30 frutos, e durante o menor, ao redor de 10 frutos. Embora as safras foram pronunciadas, havia alguns frutos nas 12 árvores na maioria dos meses do ano. Fownes \& Raynor (1993) observaram que a maioria das cultivares da fruta-pão de massa tiveram apenas um pico de produção num regime climática quase sem estações, muito diferente das observações aqui relatadas, embora Rajendran (1992) afirma que a maioria das cultivares da fruta-pão de massa florecem e frutificam ao longo do ano. A maturação dos frutos da fruta-pão levou de 60 a 90 dias após a fecundação, fato isto também relatado por Purseglove (1968). Observou-se ainda que os frutos foram mais atacados por fungos durante a época chuvosa que na época de estiagem.

$\mathrm{Na}$ jaca, o desenvolvimento dos frutos também ocorreu quase concomitante à floração (Fig. 2D), mas a ocorrência dos picos de safra foi menos regular que na fruta-pão. Em 1988 , houve um pico grande no início do ano (época chuvosa), seguido por um pico na época de estiagem. Em 1989, o pico da época chuvosa foi inexpressiva, enquanto o pico da época de estiagem foi similar ao do ano anterior. $\mathrm{Na}$ Índia, a jaca normalmente produz no início do ano, embora também pode produzir no início do segundo semestre (Teaotia \& Chauhan, 1969), embora a relação com a chuva não foi explicada. A jaqueira teve frutos nas árvores durante a maioria do meses, com um mínimo no final da época de estiagem e início da época chuvosa (novembro a fevereiro). Ao longo das observações, houve uma redução gradual no número de frutos produzidos sugerindo mais uma vez o esgotamento de nutrientes no solo. A maturação dos frutos da jaca levou de 120 a 150 dias, como observada também na Índia (Teaotia \& Chauhan, 1969).

\section{Mudança Foliar}

Tanto na fruta-pão como na jaca, a mudança foliar ocorreu depois da safra, como na maioria das fruteiras estudadas por Falcão (1993). Supõe-se que a senescência foliar seja devido à translocação de fotoassimilados e minerais das folhas para os frutos (Browning, 1985).

\section{Vingamento}

O vingamento das inflorescências femininas da fruta-pão foi considerado alto no inicio das observações (98\% no segundo semestre de 1987) e caiu para $60 \%$ no 

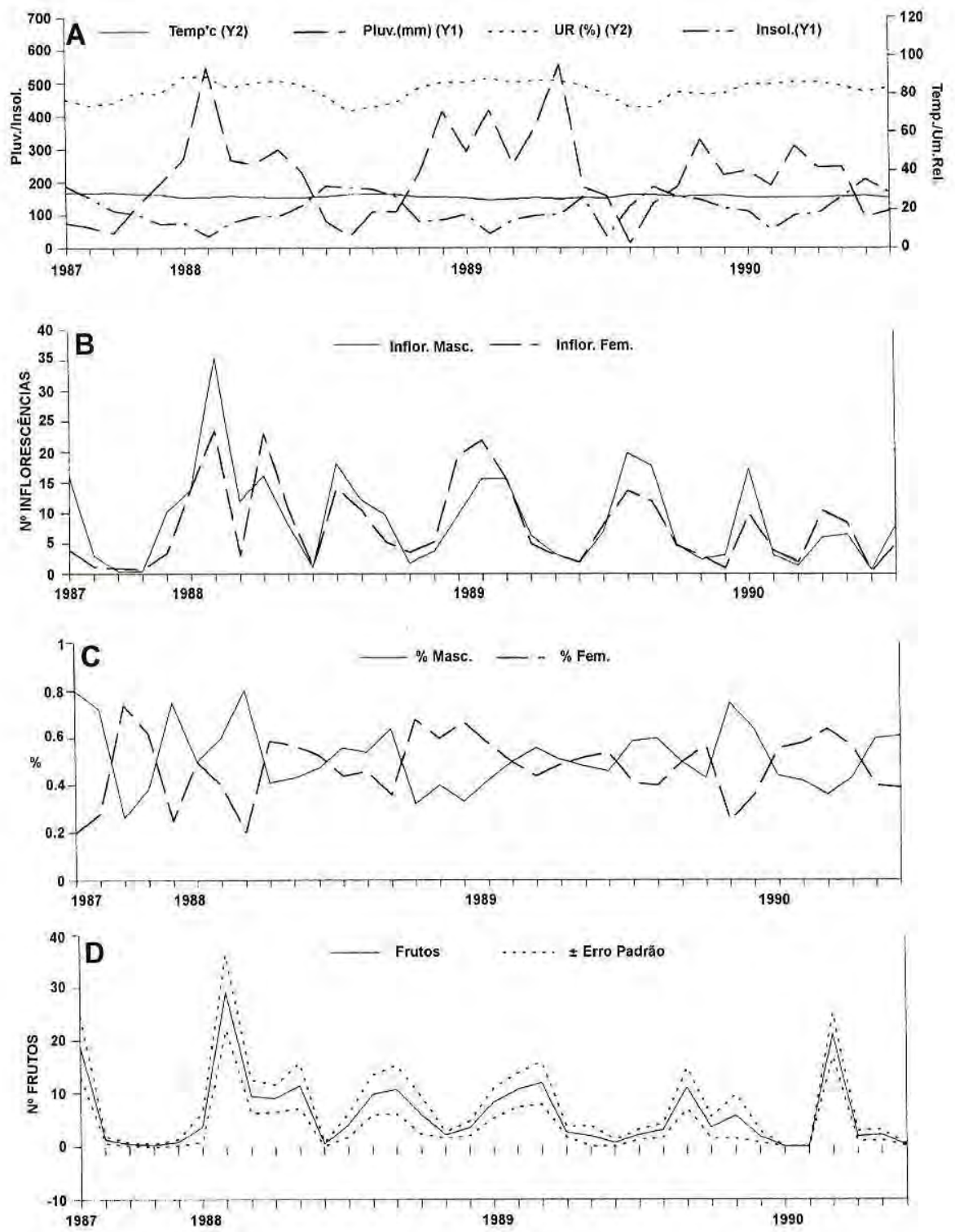

Figura 1. Fenologia da fruta-pão (Artocarpus altilis) na Amazônia Central de agosto 1987 a junho 1990. A. Dados climatológicos de Manaus. B. Número de inflorescências masculinas e femininas observadas por mes. C. Percentagem de inflorescências masculinas e femininas observadas por mes. D. Número de frutos nas árvores por mês. 

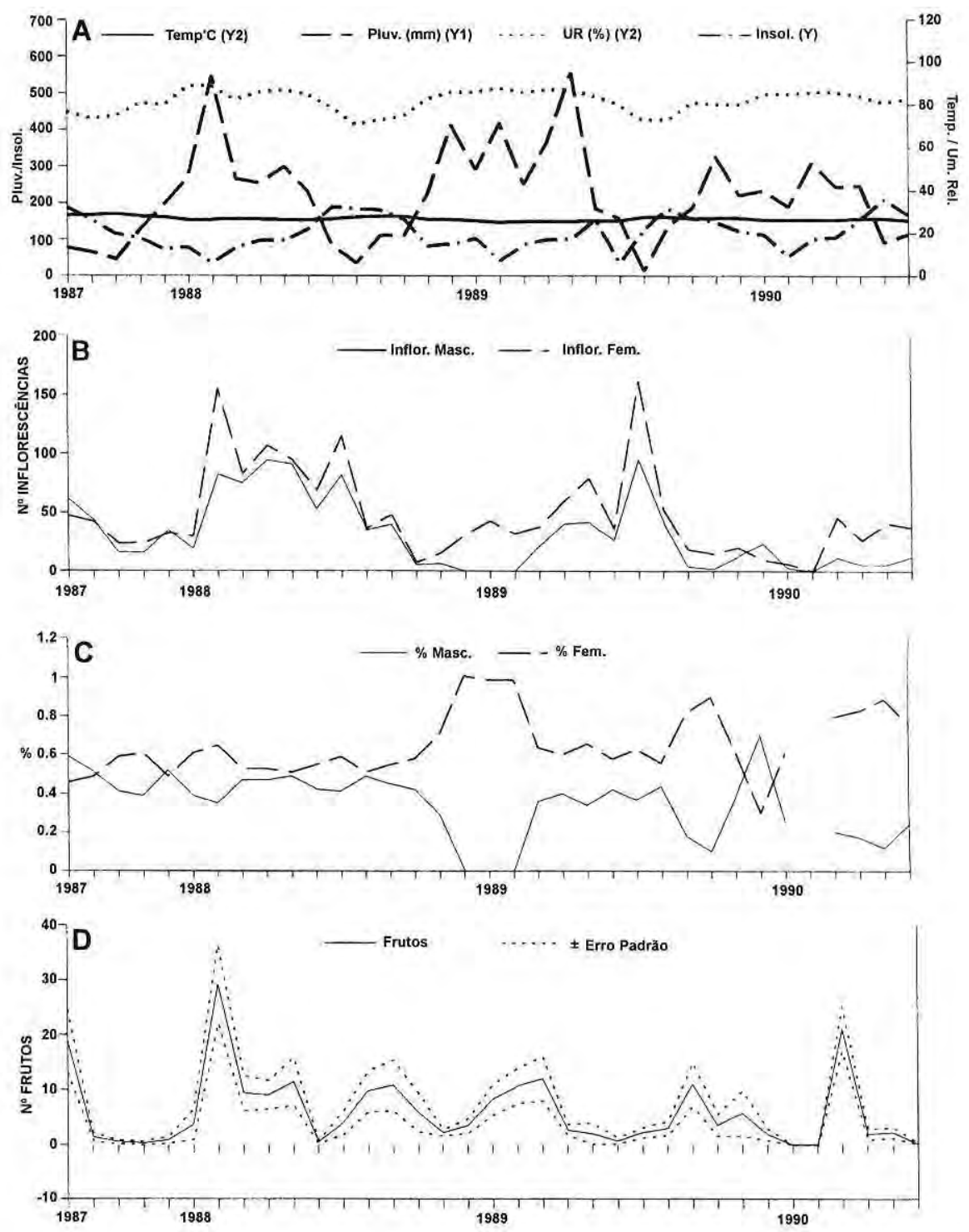

Figura 2. Fenologia da jaca (Artocarpus heterophylus) na Amazônia Central de agosto 1987 a junho 1990. A. Dados climatológicos de Manaus. B. Número de inflorescências masculinas e femininas observadas por mes. C. Percentagem de inflorescências masculinas e femininas observadas por mes. D. Número de frutos nas árvores por mês. 
primeiro semestre de 1989 , inflorescências femininas da jaca das observações (Fig. 3A), com média \pm d.p. de $76 \pm 14 \%$ por semestre. Rajendran (1992) relatou que ao redor de $75 \%$ das inflorescências femininas vingam, que concorda com nossas observações. Rajendran (1992), no entanto, afirmou que o vingamento é reduzido na época chuvosa, que não ocorreu em 1988, mas ocorreu em 1989. O padrão de vingamento não foi claramente relacionado com a chuva no periodo das observações; em lugar deste, houve uma redução gradual até meados das observações, seguida por uma recuperação gradual, embora parcial. As razões deste padrão não são claras. também foi alta no início das observações $(80 \%)$, caindo drasticamente no primeiro semestre de $1989(20 \%)$ antes de aumentar novamente no final das observações, com média \pm d.p. de $48 \pm 22 \%$ por semestre. $\mathrm{O}$ padrão de vingamento da jaca seguiu ao da fruta-pão, embora o vingamento tenha sido sempre menor.

\section{Produtividade}

A produtividade da fruta-pão depende do número de flores produzidas, o vingamento, o aborto de frutos antes de sua maturação, o número de frutos que chegam a madurecer e o número de plantas/ha. A proporção de
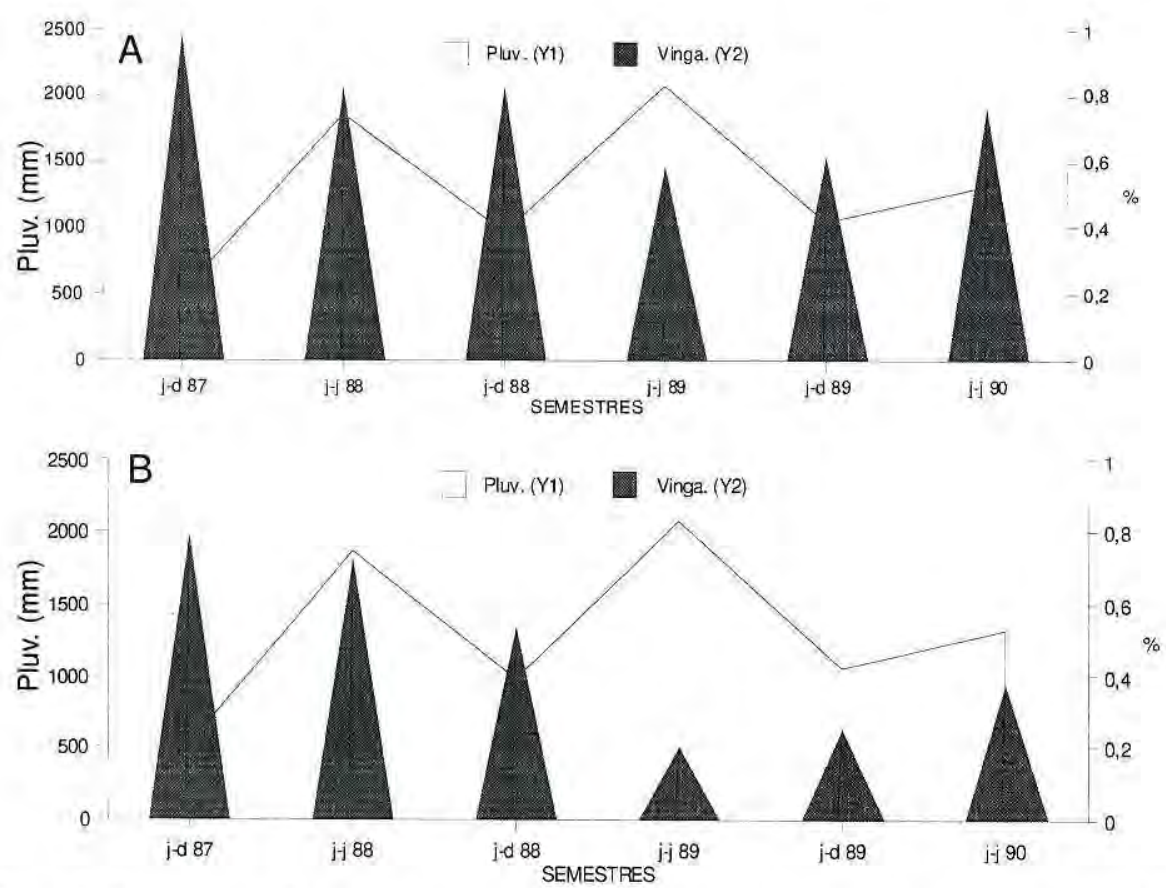

Figura 3. Percentagem de vingamento semestral em (A) fruta-pão (Artocarpus altilis) e (B) jaca (Artocarpus heterophylus) na Amazônia Central do segundo semestre de 1987 ao primeiro semestre de 1990. 
frutos caídos antes da maturação ao longo do ano variou de 33 a $39 \%$ no período, o que foi similar a proporção observada por Fownes \& Raynor (1993) na fruta-pão de massa na Oceania (média 34\%, intervalo 9 a $65 \%$ ). O número médio de frutos maduros colhidos das árvores foi 48 (Tab. 1), com pouca variação de ano a ano. Este número é muito inferior à produção observada por Fownes \& Raynor (1993), de 100 frutos/planta, provavelmente porque os solos de Pohnpei são de origem vulcânico, enquanto os da Amazônia central são pobres em nutrientes. Seguindo Barrau (1976), árvores da fruta-pão de massa produzem de 50 a 150 frutos na Oceania, cerca 200 frutos na Índia, com um máximo registrado de 700 frutos.

Em 1987, a maioria dos frutos maduros foram colhidas em abril e maio, embora havendo alguns frutos disponiveis de maio até dezembro (Fig. 4A), Em 1988, a produção foi mais uniforme ao longo do período de abril a dezembro. Em ambos anos houve pouca produção no primeiro trimestre, quando é o pico da estação chuvosa.

Os frutos da fruta-pão com sementes pesaram ao redor de $1 \mathrm{~kg}$ (Tab. 1), com variação de $700 \mathrm{~g}$ a 1,6 $\mathrm{kg}$. Esta variação é muito similar à observada na fruta-pão de massa na Oceania (0,8 a 1,8 kg; Fownes \& Raynor, 1993) e maior que aquela relatado por Barrau (1976: 0,4 a 1,2 $\mathrm{kg}$ ). As sementes representam ao redor de $40 \%$ do peso do fruto fresco, sendo o restante descartado.

Com base nestes dados, estimou- se que estas árvores de fruta-pão produziram ao redor de $48 \mathrm{~kg}$ cada (Tab. 1), perto do minimo relatado por Massal \& Barrau (1954), que foi de 50 a $250 \mathrm{~kg}$ /árvore. Vale lembrar que estas árvores estavam num sistema agroflorestal, de forma que a competição com as plantas ao redor poderia ter reduzido esta produção, além da qualidade do solo. A produtividade foi 4,8 $\mathrm{t} / \mathrm{ha}$ (assumindo 100 árvores/ha), muito inferior às estimativas mais comuns (16 a $30 \mathrm{t} / \mathrm{ha}$; Ragone, 1997).

$\mathrm{Na}$ jaqueira, a proporção de frutos caídos antes da maturação ao longo do ano variou de 27 a $29 \%$ no período. $\mathrm{O}$ número médio de frutos maduros colhidos das árvores foi 53 (Tab. 1), com pouca variação de ano a ano. Soepadmo (1992) relatou estimativas de 100 a 200 frutos por planta na Asia, mas considerou a maioria destas a serem altas, de forma que o número de frutos observados aqui pode ser considerado razoável, e é maior que o número relatado por Morton (1987) no oeste da Índia-25 frutos/árvore.

Em maio de 1987, ocorreu um pico de frutos maduros de jaca e houve um razoável número de frutos disponiveis mensalmente até dezembro (Fig. 4B), diferente da distribuição da produção de fruta-pão. Em 1988, a produção aumentou gradualmente de junho a dezembro. Em ambos anos houve pouca ou nenhuma produção no primeiro trimestre, que é o pico da estação chuvosa.

Os frutos da jaca pesaram ao 
redor de $9 \mathrm{~kg}$ (Tab. 1), com variação de 7 a $11 \mathrm{~kg}$. Esta variação é menor que a relatada por Soepadmo (1992), de 10 a $20 \mathrm{~kg}$. É possivel que esta diferença seja devido à imaturidade das plantas, pois só estavam no início de sua fase reprodutiva, mas também pode ser devido aos genótipos e aos solos pobres de Manaus. Diferente da fruta-pão de caroço, a jaca produz polpa em abundância (34\%) e apenas $12 \%$ de sementes. Similar à fruta-pão, cada fruto possue um grande porcentagem de casca e placenta que é descartada (43\%).

Com base nestes dados, estimouse que estas jaqueiras produziram ao redor de $475 \mathrm{~kg}$ cada (Tab, 1), bem abaixo das estimativas citadas na literatura mas acima dos dados de Malasia reportados por Soepadmo (1992), de 70 a $100 \mathrm{~kg} /$ árvore. Vale lembrar que estas árvores estavam num sistema agroflorestal, de forma que competição com plantas ao redor pode ter reduzido a produção, além destas plantas crescerem em solo de baixa qualidade e ser relativamente juvenis. Esta produção é equivalente a 47,5 t/ha (assumindo 100 árvores/ha), o que é bem maior que o Soepadmo (1992) considere real.

\section{Insetos Visitantes}

Durante as observações, verificou-se que vários insetos
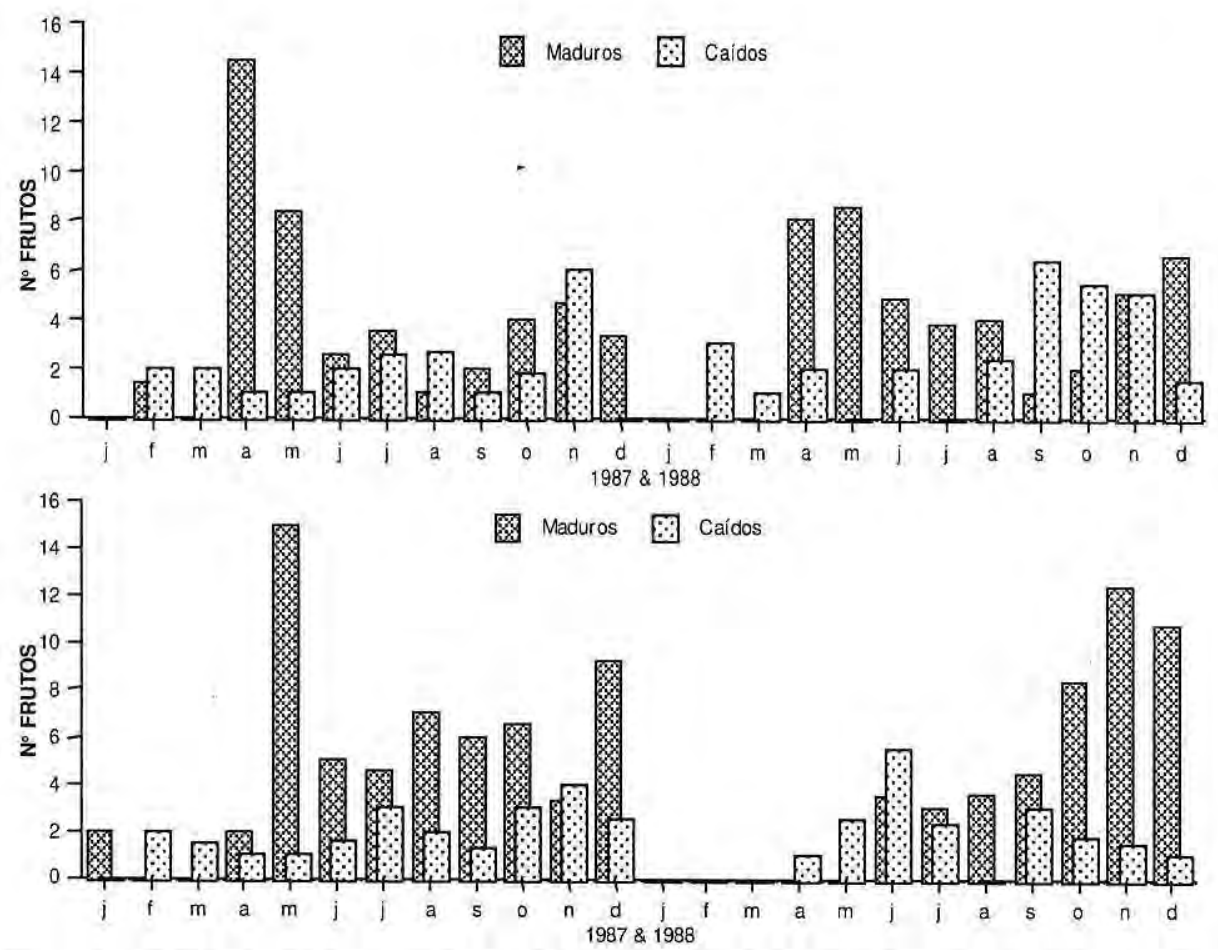

Figura 4. Fenologia de frutos caidos e maduros na Amazônia Central ao longo de 1987-88. A. fruta-pão (Artocarpus altilis). B, jaca (Artocarpus heterophylus). 
visitavam tanto as inflorescências da fruta-pão, como as da jaca. $\mathrm{Na}$ época de maior floração foram observadas as seguintes espécies: abelhas (Heminoptera: Apidae) - Melipona seminigra cfr. merrillae (Cockerell), Apis mellifera cfr. adansonii (Latreille), Plebeia minima (Gribado), Paratrigona impunctata (Ducke), Trigona sp.; formigas (Heminoptera: Formicinae) - Camponotus sp.; borboletas (Lepidoptera: Nynphalidae: Heliconiinae) - Heliconius numata (Cramer); e moscas (Diptera, Syrphidae) - Ornidia obesa (Fabricius). Ragone (1997) relata a presença de abelhas em inflorescências da frutapão, embora não seja claro se são polinizadores ou apenas coletores de pólen. Soepadmo (1992) relata a presença de moscas e besouros em inflorescências da jaca, embora também não seja claro se são polinizadores. Como ocorreu com os outros autores, não podemos afirmar que os insetos visitantes dessas árvores em Manaus são ou não polinizadores.

\section{CONCLUSÕES}

Tanto a fruta-pão como a jaca apresentam various picos de floração ao longo do ano, com a árvore de fruta-pão florescendo tanto na época chuvosa como na de estiagem, enquanto que a jaqueira floresce mais na época chuvosa. A proporção de flores estaminadas e pistiladas da fruta-pão alterna de floração à floração, enquanto que na jaca esta proporção geralmente favorece às flores pistiladas. Os frutos da fruta-pão estão presentes durante a maioria do

Tabela 1. Componentes dos frutos de fruta-pão (Artocarpus altilis) e jaca (A. heterophylus) avaliados em 1984 e 1986, respectivamente, na Amazônia Central e estimativas de produção por planta (dados de 1987 e 1988). Usa-se somente as sementes de fruta-pão em Manaus, enquanto tanto a polpa como as sementes de jaca são usadas.

\begin{tabular}{|c|c|c|c|c|}
\hline \multirow[b]{2}{*}{ Componente } & \multicolumn{2}{|c|}{ Fruta-pão $(n=32)$} & \multicolumn{2}{|c|}{ Jaca $(n=11)$} \\
\hline & média \pm d.p. & mín.-máx. & média $\pm d . p$. & mín.-máx. \\
\hline peso dos frutos $(\mathrm{kg})$ & $1,08 \pm 0,02$ & $0,70-1,60$ & $8,89 \pm 1,23$ & $6,7-11,0$ \\
\hline peso das sementes $(\mathrm{kg})$ & $0,45 \pm 0,15$ & $0,20-0,85$ & $1,13 \pm 0,33$ & $0,7 \pm 1,65$ \\
\hline$\%$ se mentes & $41 \pm 10$ & $13-58$ & $12 \pm 2$ & $9-16$ \\
\hline$n^{2}$ de se mentes & $53 \pm 17$ & $28-96$ & $174 \pm 52$ & $97-254$ \\
\hline peso médio das sementes $(\mathrm{g})$ & $8,7 \pm 2,1$ & $2,1-15,0$ & $6,6 \pm 0,6$ & $5,8-7,5$ \\
\hline peso da polpa $(\mathrm{kg})$ & - & - & $3,07 \pm 0,78$ & $2,05-4,30$ \\
\hline$\%$ polpa & - & - & $34 \pm 6$ & $0,25-0,46$ \\
\hline$\%$ descarte & $59 \pm 10$ & $42-88$ & $43 \pm 6$ & $41-61$ \\
\hline$n^{e}$ frutos/árvores & $45 \pm 1$ & & $53 \pm 7$ & \\
\hline produçă olárvore (kg/árv.) & $48 \pm 1$ & & $475 \pm 65$ & \\
\hline
\end{tabular}


ano, com picos de maior abundância no início da época chuvosa e no final da época de estiagem, enquanto frutas de jaca são mais abundantes nas árvores durante a época chuvosa. $\mathrm{O}$ vingamento de frutos da fruta-pão é maior que o da jaca. Tanto a fruta-pão como a jaca apresentaram acentuada caída de frutos entre o vingamento $\mathrm{e}$ a maturação, com médias de $36 \%$ e $28 \%$ por ano, respectivamente. Embora o número de frutos produzidos por planta não tenha sido muito diferente, com médias de 53 e 45 por planta, respectivamente, a produção estimada da jaca é maior (475 kg/planta) do que da fruta-pão (48 kg/planta), porque os frutos da jaca são muito maiores que os da fruta-pão, com médias de $8,9 \mathrm{~kg}$ e 1,1 $\mathrm{kg}$, respectivamente.

\section{AGRADECIMENTOS}

Agradecemos ao Dr. Francisco J. Peralta, Laboratório de Entomologia do Instituto Nacional de Pesquisas da Amazônia (INPA), pela identificação dos insetos; a Ms. Biatriz RonchiTeles pela correção dos nomes científicos dos insetos; a Maria José Printes Silva Rolim, Maria Gracimar Pacheco de Araújo e Rozana M. Galvão, pela ajuda no laboratório e manejo dos dados; a $\mathrm{Dr}^{\mathrm{a}}$ Marlene Freitas da Silva, pelas criticas e sugestões sobre o manuscrito.

\section{Bibliografia citada}

Arkcoll, D.B. 1982. Considerações sobre a produção de alimentos por árvores $\mathrm{e}$ florestas. Acta Amazonica, 12(2):247-249.
Barrau, J. 1976. Breadfruit and its relatives: Artocarpus spp. In: Simmonds, N.W. (Ed.). Evolution of Crop Plants. Longman, London. pp. 201-202.

Bennett, F.D.; Nozzollilo, C. 1988. How many seeds in a seeded breadfruit, Artocarpus altilis (Moraceae)? Economic Botany, 41(3):370-374.

Browning, G. 1985. Reproductive behavior of fruit tree crops and its implications for the manipulation of fruit set. In: Cannel, M.G.; Jackson, J.E. (Eds.). Attributes of trees as crop plants. Inst. Terrestrial Ecology, NERC, Huntingdon, UK. pp. 409425 .

Cavalcante, P.B. 1991. Frutas comestiveis da Amazônia, $5^{\text {a }}$ Ed. Edições CEJUP, Belém. 279 p.

Corrêa, M.P, 1926. Dicionário das plantas úteis do Brasil e das exóticas cultivadas. Serviço de Informação Agricola, Rio de Janeiro. Vol, 3, pp. 340-345.

Falcão, M. de A. 1993. Aspectos fenológicos, ecológicos e de produtividade de algumas fruteiras cultivadas na Amazônia. Volume II. Univ. Amazonas, Manaus. 97p.

Fownes, J.H.; Raynor, W.C. 1993. Seasonality and yield of breadfruit cultivars in the indigenous agroforestry system of Pohnpei, Federated States of Micronesia. Tropical Agriculture (Trinidad), 70(2):103-109

Jarrett, F.M. 1976. The syncarp of Artocarpus - a unique biological phenomenon. Gardener's Bull. (Singapore), 29:35-39.

Massal, M.; Barrau, J. 1954. Pacific subsistence crops: Breadfruit. South Pacific Bull. $4(4): 24-26$.

Morton, J. 1987. Breadfruit. In: Morton, J. (Ed.). Fruits of warm climates. Morton Collectanea, University of Miami, Coral Gables, FL. pp. 50-58.

Narasimhan, P. 1990. Breadfruit and Jackfruit. In: Nagy, S.; Shaw, P.E.; Wardowski, W.F. (Eds.). Fruits of tropical and subtropical origin - composition, properties and uses. Florida Science Source, Lake Alfred, FL. pp. 193-259.

Negron de Bravo, E.; Graham, H.D.; Padovani, 
M. 1983. Composition of the breadfruit (seeded breadfruit). Caribbean J. Sci., 19(3-4):27-32.

Patiño, V.M. 1969. Plantas cultivadas $y$ animales domesticos en América Equinoccial. Tomo IV. Plantas introducidas. Imprenta Departamental, Cali, Colombia. 573p.

Prance, G.T.; Silva, M.F. 1975. Arvores de Manaus. Instituto Nacional de Pesquisas da Amazônia, Manaus. 312p.

Purseglove, J.W. 1968. Artocarpus altilis. In: Purseglove, J.W. Tropical crops - Dicotyledons. Longman, London. pp. 379-384.

Quijano, J.; Arango, G.J. 1979. The Breadfruit from Colombia - a detailed chemical analysis. Economic Botany, 33(2):199202.

Ragone, D. 1997. Breadfruit, Artocarpus altilis (Parkinson) Fosberg. Promoting the conservation and use of underutilized and neglected crops. 10. Institute of Plant Genetics and Crop Plant Research, Gatersleben/ International Plant Genetic Resources Institute, Rome, Italy, 77p.

Rajendran, R. 1992. Artocarpus altilis (Parkinson) Fosberg. In: Verheij, E.W.N.; Coronel, R.E. (Eds.). Plant resources of South-East Asia, No. 2: Edible fruits and nuts, Prosea, Bogor, Indonesia. pp. 83-86.

Ribeiro, M.N.G. 1976. Aspectos climatológicos de Manaus. Acta Amazonica, 8(2):229-233.

Soepadmo, E. 1992. Artocarpus heterophyllus Lamk. In: Verheij, E.W.N.; Coronel, R.E. (Eds.) Plant resources of South-East Asia, No. 2: Edible fruits and nuts. Prosea, Bogor, Indonesia. pp 86-91.
Teaotia, S.S.; Chauhan, R.S. 1969. Studies on the bearing habits, floral biology and fruit development in jackfruit (Artocarpus heterophyllus Lam.). Hortic. Sci., 1(2):29-37.

Thomas, C.A. 1980. Jackfruit (Artocarpus heterophyllus) Moraceae, for food and income. Economic Botany, 3:154-159.

Wielgolaski, F.E. 1974. Phenology in agriculture. In: Lieth, H. (Ed.). Phenology and seasonality modeling. Chapman \& Hall, London. pp.369-381. 